\title{
CRITERIA FOR THE ASSIGNMENT OF RESPONSIBILITIES FOR DISTURBANCES BETWEEN UTILITY AND LOAD IN DISTRIBUTION NETWORKS
}

\author{
Pedro E. ISSOURIBEHERE \\ IITREE-UNLP - Argentina \\ pedroi@iitree-unlp.org.ar
}

\author{
Gustavo A. BARBERA \\ IITREE-UNLP - Argentina \\ gbarbera@iitree-unlp.org.ar
}

\section{INTRODUCTION}

Since 1997 Utilities in Argentina have been required by the Regulatory Authority (Ente Nacional Regulador de la Electricidad - ENRE) to carry out severe monitoring programs. These monitoring programs involve measuring both voltage level and disturbances - harmonics and flicker in different points of their networks.

There are regulations related to these monitoring programs which set the rules to be followed by the Utilities. Such regulations include the limits that must be fulfilled.

As regards disturbances measurements, if the values measured in voltage are above the limits established Utilities are fined. One the other hand, Utilities are able to explore their networks in order to search for disturbing customers. In addition, Utilities are also able to fine customers as long as it is correctly proved that such disturbances are caused by them.

Most procedures currently employed to decide whether the disturbances measured at a generic Point of Coupling (PC) are produced by the customer or by the Utility are difficult to carry out in practical cases.

The aim of this paper is to analyse and criticise these procedures and propose new, more simplistic methods to assess responsibilities for disturbances. These are related to other methods also applied to different procedures regarding Liberalized Electricity Markets.

\section{NETWORK-CUSTOMER MODEL}

As far as responsibilities for waveform quality is concerned, it is appropriate to treat the subject at a generic point of coupling. This PC could represent the interface between a transmission system and a distribution company as well as the interface between the distribution company and a customer. Regardless of which case is being analysed, the electrical system can always be represented by the simple model shown in Fig. 1, where the point of coupling is generic. In this model the PC is the place in which the demand is measured.

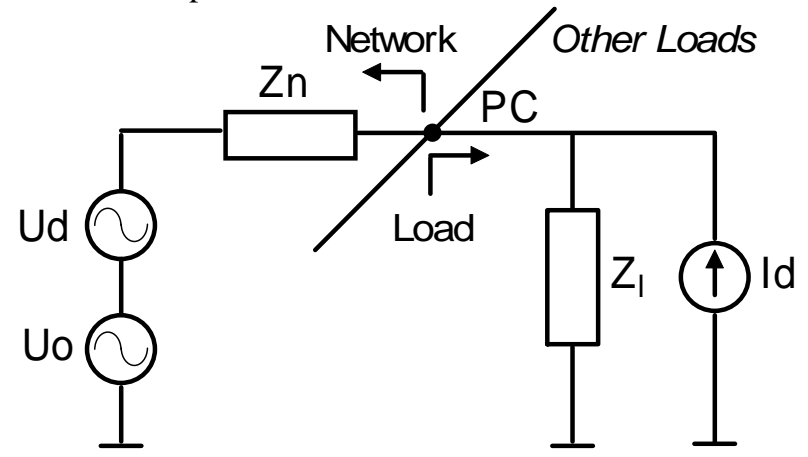

Fig. 1. Model of compatibility between network and customer.

Where:

Uo: Thevenin's voltage at $50 \mathrm{~Hz}$.
Ud: Thevenin's voltage representing a generic disturbance. This is not produced by the customer but by the utility.

$\mathrm{Zn}$ : Thevenin's impedance seen from the PC.

$\mathrm{Z}_{1}$ : Load impedance. It includes both active and reactive power.

Id: Norton's current representing the same type of disturbance as Ud but in this case injected by the customer.

In the figure other loads fed from the same PC have also been represented.

In order to accomplish the required compatibility levels at the PC, first susceptible loads are supposed to withstand the existing disturbances, and second the network must be capable of absorbing disturbances emitted by consumers.

Consequently, the network must not only supply $50-\mathrm{Hz}$ power but also has to be capable of keeping voltage waveform at the PC according to standards.

\section{RESONSIBILITY FOR VOLTAGE VALUE AT 50 HZ}

Long-interval-averaged voltage magnitude

The network supplies energy at $50 \mathrm{~Hz}$ and a non-disturbing load requires energy only at this frequency.

Voltage magnitude at PC - $\mathrm{U}_{1}$ - depends on both sendingvoltage - Uo - and voltage drop across the network impedance - $\Delta U$. This is depicted in Fig. 2.
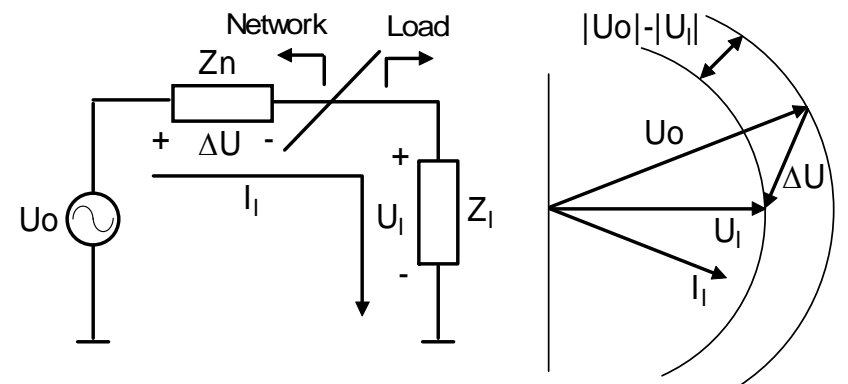

Fig. 2. Model to represent the voltage magnitude issue.

Despite being both utility and customer responsible for the voltage magnitude, the rules fixed in Argentina state that the whole responsibility lies on the utility.

This criterion means that the utility not only supplies power to the customer but also has to be capable of delivering a voltage average magnitude within certain range.

The standards establish that the voltage must be averaged over the same long intervals as demand is averaged. In Argentina it is a 15-min interval.

Therefore, the utility will have to design its networks according to the load so as to achieve the required voltage level. On the other hand, consumers must not exceed the maximum agreed demand and must fulfil the power factor requirements as well.

On the whole, even though the voltage magnitude is due to both utility and customer as the major influence lies on the utility, this is responsible for it. 


\section{Voltage sags}

Sags are perturbing phenomena which consists of short transgressions of the voltage value limits. When these are extremely short, they are similar to microinterruptions.

The larger amounts of susceptible loads consumers include in their installations, the more important these sorts of disturbances are.

Normally, such phenomena are produced by the system itself (e.g. outages of some components). Nevertheless, they can also be caused by consumers' overloads.

In Fig. 3 this kind of disturbance is represented.

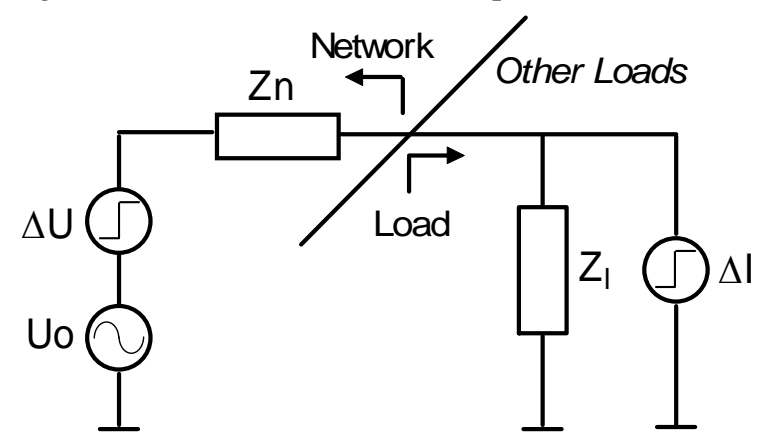

Fig. 3. Model to represent responsibilities for voltage sags.

Where:

$\Delta \mathrm{U}$ : Thevenin's voltage representing voltage sags caused by the system.

$\Delta \mathrm{I}$ : Norton's current corresponding to sudden changes in the load.

Obviously, this situation is rather similar to the one above described since the same components of the system take part. The main difference lies on the averaging interval that is considered. While in voltage magnitude a 15-min interval is performed, in this issue the interval length is much shorter. In addition, cause-effect mechanism is also different. In order to keep the voltage average value within the limits it is possible to use typical system components such as voltage regulators, whereas for sags and short interruptions it is necessary to employ more sophisticated devices such as static compensators.

In Argentina they still have not fixed the rules to assign responsibilities for this issue. However, some companies have set procedures that deal with the connection of disturbing loads to their networks. When new customers are to install industrial loads, they are requested to provide some technical information about them. In this manner, it is possible to design the feeder taking into account such perturbing loads. The standards to be set in the future should consider both the depth of sags and their occurrence rate. On the other hand, the degree in which the agreed demand can be exceeded by customers as well as their rate of occurrence should also be established.

A suitable solution to this issue could be shortening the present demand intervals (15-min). As a consequence, due to the higher incomes received by utilities it would be possible to carry out further investments in the system so as to keep the voltage magnitude (averaged over the same period as demand) within the limits over shorter intervals.

\section{RESPONSIBILITY FOR HARMONICS}

As far as harmonic issue is concerned, it is possible to employ the model that it is depicted in Fig. 4.

There are international standards concerning harmonics. Both IEEE and IEC standards establish limits to individual harmonics. In Argentina, the Regulatory Authority has fixed its own limits for both voltage [1] and current [2] harmonics.

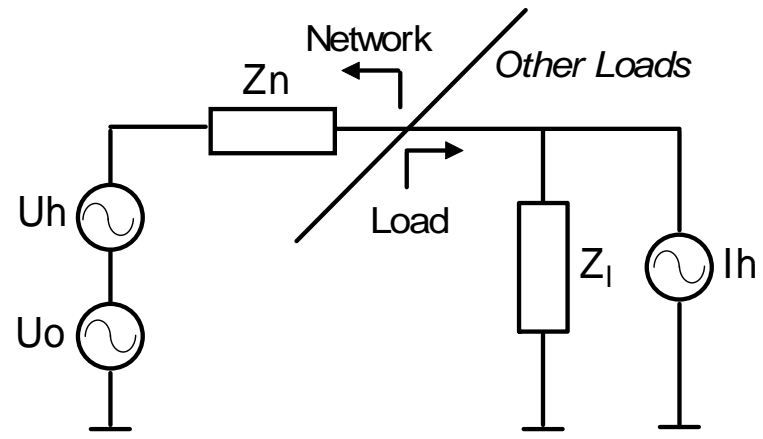

Fig. 4. Model proposed to assess responsibilities for harmonics.

Where:

Uh: Thevenin's voltage representing one harmonic (there must be as many generators as harmonics are considered). They are harmonics produced by the system.

Ih: Norton's current corresponding to harmonics caused by the customer.

Voltage harmonics affect susceptible loads, whereas current harmonics emitted by consumers must be as low as possible so as not to affect the system voltage. Both limits are applied separately.

The international standards as well as the Argentinian - based on the previous ones - establish first the limits for voltage and then the limits for currents emitted by customers. In Argentina, the emission limits were adjusted by performing a previous monitoring program in which harmonics at different voltage levels were measured.

Both requirements are applied separately. On the one hand, the Regulatory Authority verifies that the utility fulfils voltage harmonic levels [1]. On the other hand, the utility is able to control disturbing consumers [2].

In certain cases it is difficult to determine responsibilities for harmonics. As regards voltage harmonics, it can be stated that they are utility's responsibility. This statement is based on the same principle used for voltage magnitude issue.

In contrast, when harmonic currents are over the allowable values it is necessary to determine their origin. Usually, the following question comes out: are these harmonic currents due to the Uh generator included in Fig. 4? Or are they produced by the non-linear load represented by the Ih generator?

The harmonic flow is similar to the $50-\mathrm{Hz}$ power flow. At a PC which connects customers (downstream) to the system (upstream) it is possible to answer the question by applying superposition. The resulting flow will depend on both, the one flowing from the system and the one flowing from the loads. Disturbing loads take power at $50 \mathrm{~Hz}$ and convert part of it into harmonics.

Consequently, when high harmonic levels are measured at certain PC it is necessary to determine who is to blame for this. The method currently used is based on harmonic active power flow.

This method requires measuring voltage, current and phase between them for each harmonic from $2^{\text {nd }}$ up to $40^{\text {th }}$. If harmonics flow in the same direction as active power positive harmonic power - it means that the disturbance is caused by the utility. On the contrary, if they flow in the opposite direction - negative harmonic power - the disturbance appears to be produced by the customer.

However, even though this method is theoretically correct, in 
practical cases there is a point to consider. Most networks have an inductive/capacitive behaviour rather than resistive, especially for high-order harmonics. Consequently, voltage and current harmonics tend to be in quadrature as it is depicted in Fig. 5 for a generic harmonic.
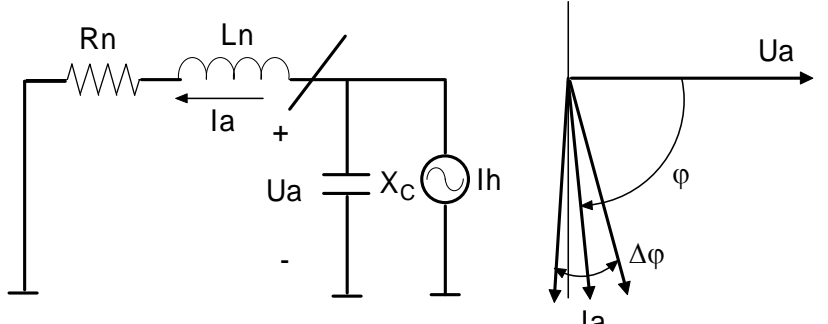

Fig. 5. Model and phasor diagram for typical cases.

If the angle between Uh and Ih is lower than $90^{\circ}$, the harmonic power is positive and the disturbance is caused by the utility. In contrast, if the angle is over $90^{\circ}$ the harmonic power is negative and the disturbance is produced by the customer.

Nevertheless, the equipment that utilities use for measuring harmonics includes current clamps whose angle error can be as high as $5^{\circ}$ according to IEC standards. As a consequence, due to this measuring error it is possible to reach a wrong conclusion regarding harmonic generation and blame either utility or customer unfairly.

Therefore the following simpler procedure to assess responsibility is recommended: Both voltage and current harmonics must be measured and then compared with the established limits. If harmonic voltage levels are over the limits the utility is supposed to fix the problem regardless of who has caused it. On the other hand, if the harmonic current levels are not within the established limits the customer ought to solve the problem by using filters or replacing the disturbing load.

On the whole, voltage quality is utility's responsibility while current quality is customers' responsibility such as is accepted in voltage magnitude regulations.

This simple, general rule should not be applied in particular cases such as large disturbing loads connected to a PC, where a more detailed analysis of the subject is required.

One of the analysis that are normally carried out in particular cases consists of representing in a same graph both voltage and current harmonics.

This sort of diagrams together with the study of loads behaviour allows identifying harmonic source.

The graph obtained in this occasion is shown in Fig. 6, where the $11^{\text {th }}$ harmonic has been represented.

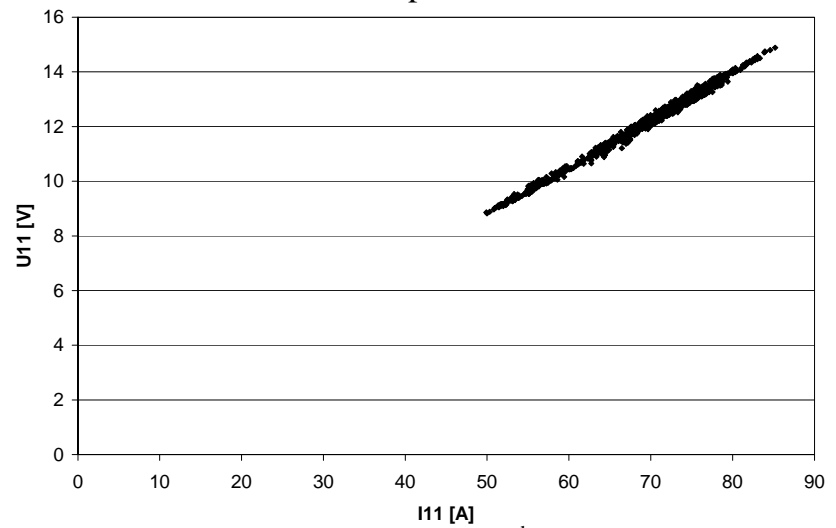

Fig. 6. Current vs. voltage harmonics. $11^{\text {th }}$ harmonic.

The normalised harmonic measurements performed in Argentina are one-week long. They are divided into 10-min interval; consequently throughout the whole week 1008 10min intervals are recorded.

For each 10-min interval both current and voltage harmonic are represented in abscissas and ordinates respectively. Once all pairs have been represented the graph of Fig. 6 is obtained. In this particular case - telephonic central including rectifiers - voltage as well as current harmonics exceeded the limits. Consequently, it was necessary to determine who was causing the problem.

By means of the following procedure it was possible to achieve the goal of identifying the harmonic source. First, it was obtained the straight line that best fitted all the points. Then, the ordinate to origin of this straight line conceptually would be the $11^{\text {th }}$ harmonic voltage content if the $11^{\text {th }}$ harmonic current were null. In this case such a value was considerably under the established limits. As a conclusion, the Uh generator of Fig. 4 was neglected and the harmonic problem was caused by the Ih generator. To sum up, the customer was responsible for this issue and was requested by the utility to include filters in the installation.

Other method also utilised to determine the origin of disturbances suggests measuring voltage and current simultaneously over a period of time. If possible, during part of this period, the loads that appear to emit disturbances are disconnected from the system. Thus, the harmonic levels measured in voltage represent the Uh generator in Fig. 4.

This method was also employed to determine the harmonic source in another difficult case. In this occasion, the customer that was thought to have been perturbing was a pumping station that included in its installations a motor drive producing several harmonics in the ac-dc conversion.

Because of utility requirements harmonics were measured at PC. Again, high values of both voltage and current were recorded. In this case the harmonic over the limits was the $5^{\text {th }}$. In order to determine its origin a 5-day measurement was made. During this period the plant was pumping for only the first day, the rest of time it was out of service and only the auxiliary services were connected.

The results are depicted in Fig. 7 . It shows the $5^{\text {th }}$ harmonic voltage as well as the active power consumed by the plant.

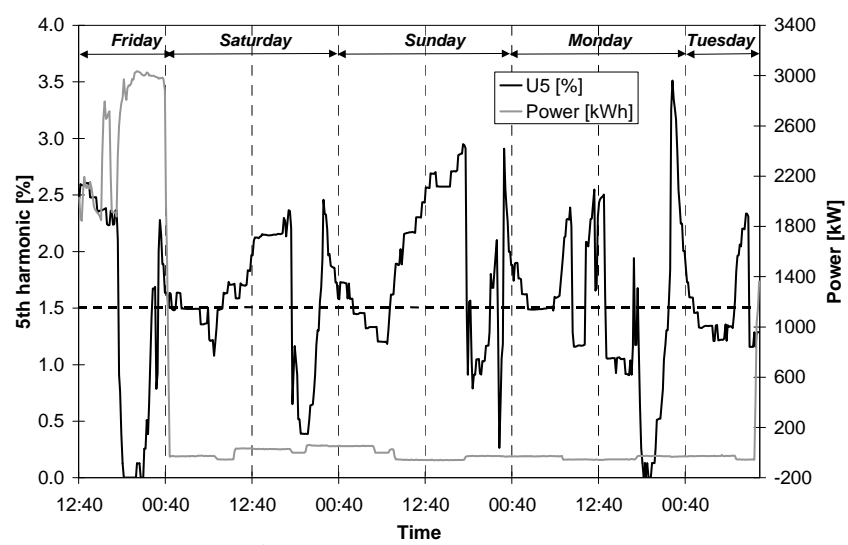

Fig. 7. Power and $5^{\text {th }}$ harmonic voltage at a pumping station.

These results were really helpful. While power values were high only during the first day, the $5^{\text {th }}$ voltage harmonic remained low in the evening and high the rest of the day throughout the whole measuring period. In fact, the highest values were recorded when the plant was not operating. As a conclusion, it could be affirmed that in this occasion the disturbance was not caused by the customer but by the utility. These harmonics might have been produced by another customer, as their behaviour was rather similar everyday. 


\section{RESPONSIBILITY FOR FLICKER}

Flicker is also regulated in Argentina [1] [2]. As it was presented in the previous section, in harmonic regulations both voltages and currents have their allowable values. Nevertheless, as far as flicker regulation is concerned maximum values were only fixed for voltage.

This is based on the fact that flicker is normally associated to the annoying effect that a light supplied by a flicker- polluted voltage produces on people.

However, when high flicker values are found somewhere, they may also be produced by certain customer. Therefore, when it is necessary to determine whether flicker is caused by a customer or not, regulations recommend measuring the voltage flicker that customer's current produces across a normalised impedance. This is the procedure recommended by IEC standards [3] [4].

The flicker emission measurement can be performed in normal operation of load by making the customer's current flow through the normalised impedance, whose resistive and inductive values are established, and measuring the voltage flicker with an appropriate recorder [5]. This procedure is shown in Fig. 8 [8].

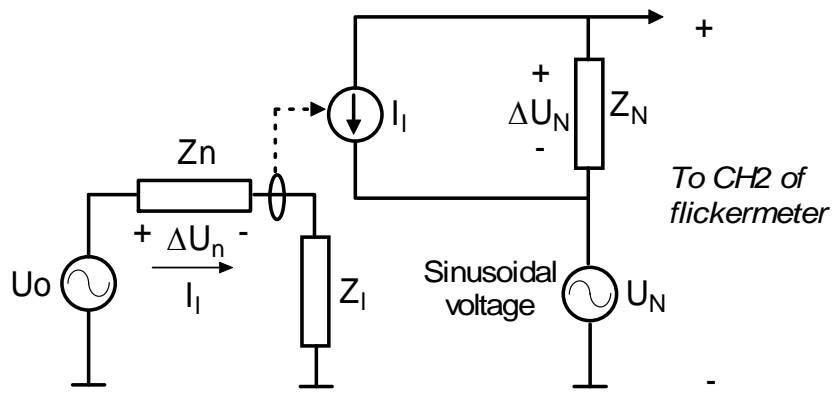

Fig. 8. Circuit to measure flicker emission.

To determine the flicker source it is required to employ a twochannel flickermeter. In one of them, flicker existing in system voltage is directly measured ( $\mathrm{CH} 1)$, while in the other voltage flicker produced on the normalised impedance is measured as well (CH2). Then, both values have to be compared to the reference levels.

If the values measured in $\mathrm{CH} 1$ are over the maximum, flicker at PC appears to be produced by the utility. On the contrary, if flicker measured in $\mathrm{CH} 2$ is above the allowable values, flicker is thought to be caused by the customer.

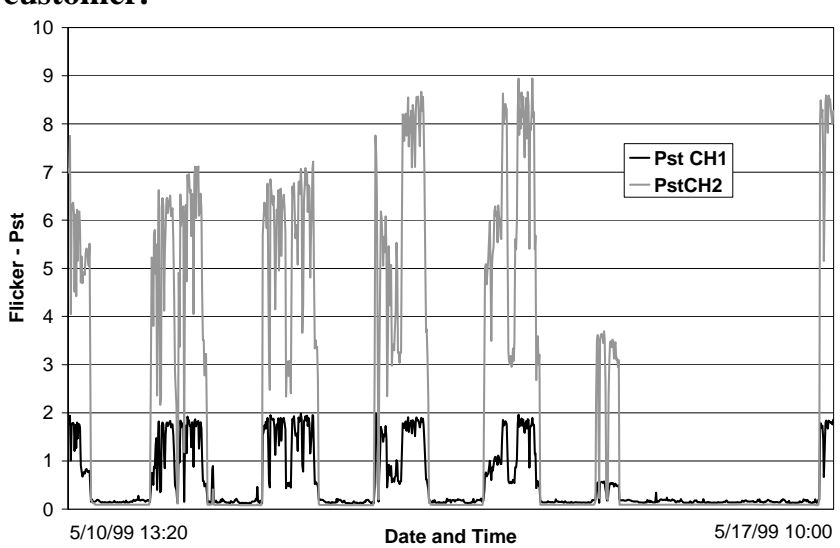

Fig. 9. Flicker measured in both channels of the flickermeter.

The above-described procedure was employed to determine responsibilities for flicker at certain PC. The main load of the customer consisted of a large arc furnace. Consequently, high flicker values were recorded at PC.

Due to such a non-linear load flicker was expected to be caused by the customer. Nevertheless, a normalised measurement of flicker emission was performed.

The results obtained are shown in Fig. 9, where Pst values have been represented. They were as expected, considerably higher voltage flicker levels across the normalised impedance were recorded.

As a consequence, it was properly proved that system voltage was polluted by customer's current emission and therefore the issue must be mitigated by the consumer.

\section{CONCLUSIONS}

- When high values of disturbances are measured at certain point in the system it is necessary to determine their origin. Nowadays in Argentina there are procedures to determine this origin [2].

- According to the 7-year experience of IITREE it is believed that some of these procedures, especially those regarding harmonics, are difficult to employ in practical cases.

- In the article simpler procedures are proposed. Mainly, they suggest assigning responsibility for voltage to the utility and responsibility for current to the customer. In this manner it is also accepted in voltage magnitude regulations [1] and in consumers' demand control. If such simpler procedures were applied in methods of general control - i.e. monitoring programs - these would be more dynamic. Nevertheless, in some particular cases they could not be utilised and further analysis should be carried out.

\section{REFERENCES}

[1] ENRE 184/00. Base Metodológica para el Control de la Calidad del Producto Técnico. Etapa 2.

[2] ENRE 99/97. Base Metodológica para el Control de la Emisión de Perturbaciones. PT. Etapa 2.

[3] IEC 61000-3-3. Electromagnetic Compatibility (EMC). Part 3: Limits. Section 3: Limitation of voltage fluctuations and flicker in low-voltage supply systems for equipment with rated current $\leq 16 \mathrm{~A}$.

[4] IEC 61000-3-5. Electromagnetic Compatibility. Part 3: Limits. Section 5: Limitation of voltage fluctuations and flicker in low-voltage power supply systems for equipment with rated current greater than $16 \mathrm{~A}$.

[5] IEC 868 (IEC 61000-4-15). Flickermeter. Functional and design specification.

[6] IEC 61000-4-7. Electromagnetic compatibility (EMC) Part 4-7: Testing and measurement techniques - General guide on harmonics and interharmonics measurements and instrumentation, for power supply systems and equipment connected thereto.

[7] C. Guidi y P. Issouribehere. "Voltage Quality. Experiences from the Control of Distribution Services". Congreso Internacional de Redes Eléctricas de Distribución CIRED ARGENTINA'96. Buenos Aires. 2 al 5 de diciembre de 1996.

[8] P. Issouribehere y D. Esteban. “Medición de la emisión de flicker por cargas perturbadoras mediante un simulador de red normalizada”. VIII Encuentro Regional Latinoamericano de CIGRE (VIII ERLAC). Ciudad del Este, Paraguay. Junio, 1999. 